\title{
EDITORIAL
}

\section{GEOSCIENCE CANADA - The Road Ahead}

It is my pleasure to welcome you to volume 43 of Geoscience Canada as its new scientific editor, and also on behalf of the greater team that makes this journal a reality. In the year since I became the 'editor-in-training,' many of my preconceptions about the publishing process have been demolished, but I have gained some new and valuable perspectives. I am keenly aware that there is much left to learn, but thanks to the efforts of Brendan and Cindy Murphy, the road ahead now seems much clearer and a little less steep. I would also like to thank Chris White and Sandra Barr of Geological Association of Canada (GAC) Publications for their encouragement to take on this role, and for their advice and assistance.

My first task is to thank our outgoing editor, Brendan Murphy of St. Francis Xavier University in Nova Scotia. There have been many significant changes in the format and content of Geoscience Canada under his stewardship. In 2011, we moved to a digital and online format - a move dictated in part by the growing cost of producing a printed journal. However, this transition went beyond dollars and cents, as freedom from the constraints of the printed page opened many new possibilities. The size of individual issues - and the length and complexity of individual articles - is no longer strictly limited by printing costs. Colour illustrations and eye-catching photographs are now standard accessories for any article, and links to other sources and articles can be embedded in the text. We are indebted to the University of New Brunswick in Fredericton for hosting the online journal, and we owe particular thanks to James Kerr and Michael Nason for assistance with this vital aspect of today's Geoscience Canada.

The leap from printed page to PDF was just the first of the many changes. In 2013, Geoscience Canada became a stand-alone journal, meaning that access to our content was decoupled from membership in the GAC. This does not sever links between the journal and GAC, nor does it indicate that we no longer serve GAC's objectives, but it has given us greater visibility and impact on national and international levels. This has broadened our readership, widened the scope of contributions and encouraged more submissions. In time, we hope that it will bring increased visibility and membership growth for GAC itself. These changes in Geoscience Canada can be directly measured. Our last pre-digital volume (2011) contained 164 pages; this grew to 204 pages in 2012 , to 382 pages in 2013 , to 584 pages in 2014 and to 492 pages in 2015. This trend reflects increasing numbers of papers, and longer papers, covering an increasingly wide range of topics. We are indebted to Brendan for his energy and enthusiasm, his ability to connect with scientists in many different fields and his legendary talent for persuading authors to write! It has been said that there are good editors and there are popular editors, but being both of these at once can be a challenge. Brendan managed it with great skill and insight, and will continue to do so as one of the science editors of Geology. I hope also to continue to benefit from his advice from time to time.

Encouraging papers, and seeing them through peer review, is only the first step in a lengthy process. Our managing editor, Cindy Murphy, looks after the downstream part of the editorial pipeline, where text, references, figures, photographs and other things all come together into a final seamless product. It takes a great deal of work and communication with authors to bring articles to this stage. I am enormously grateful that Cindy will continue this role in the years to come, and thank her sincerely for orienting me to my tasks and keeping me on time as this issue developed. We also owe great thanks to hard-working volunteer copy editors who take the time to ensure that the authors' work is represented in a clear and accurate manner, with the style consistent to the journal's format. Last but not least, we also owe thanks to Bev Strickland in St. John's, whose skills with the layout and formatting of articles are indispensable. Karen Dawe at GAC Headquarters in St. John's will continue her important work to promote the journal and manage subscriptions, and devise initiatives to enlarge our readership base. In the last twelve months, I have come to understand that I am just the newest member of a well-established and very efficient team, and that team effort and coordination are essential in everything that we do. I have no doubt that we can continue our record of timely assembly and production of each issue throughout volume 43 and beyond.

Geoscience Canada has now served the diverse Canadian Geoscience Community for over 40 years. Our founding editor Gerry Middleton envisaged a mission to publish articles about diverse topics in the Earth Sciences that would inform nonspecialist readers, rather than simply mystify them. Our science is increasingly specialized, and sometimes it seems that each sub-discipline now has its own language and incomprehensible 
vocabulary. Over the years, Geoscience Canada has sought to create a bridge to connect those who should be in communication but often are not. This intersection of ideas from diverse disciplines is truly at the heart of the Earth Sciences, and it depends upon specialists understanding the relevance of ideas and advances in other areas that are less familiar to them. The highly successful facies models and ore-deposit models thematic paper series of the past provide great examples of this philosophy, and have seen wide use as instructional materials, but they are not the only ones. You can find illuminating and readable treatments of complex topics in most issues of Geoscience Canada. This guiding principle - that the science we present should be understandable in general terms by a wide cross-section of our community - is one that I firmly believe in, and I will do everything possible to uphold it.

Over the years, our content has diversified, notably through thematic paper series in which invited and submitted papers combine to address specific problems or topics in Earth Science. In the last year, compiled papers from the Hank Williams Series and the Paul Hoffman Series were published as books, and we anticipate that the popular Igneous Rock Associations series will result in a similar product of lasting value. The current issue contains the first contributions in a new thematic series dedicated to Heritage Stone, intended to give readers insight into the origins and special features of rock types that are widely used by human society, or which have played important roles in human history and culture. The Andrew Hynes Series directed at tectonic processes will have several new contributions in Volume 43, as will other existing thematic series. The 'GAC Medallist' paper series provides overview papers by leading Earth Scientists, which integrate established concepts with new developments. These will continue, and we hope to expand boundaries to include medallists from associated Canadian geoscience societies. Finally, some long-running thematic paper series will come to an end in the coming years, so we will need to replace them with new ideas. If you have such thoughts, or are interested in taking a valuable role as a series editor, please get in touch with us. We will also continue to publish scientific articles that are independent of thematic paper series, and bring you columns, book reviews and conference reports. Suggestions on all of these topics from the readership are encouraged and welcomed.

Geoscience Canada has indeed evolved, but we need to think about its further development and growth, and what our objectives should be in the coming years. There remain fundamental challenges that we cannot ignore, even with an online format, and with much of our effort aided by volunteers, the costs of running a quality journal remain significant. We have been awarded continued funding through the Canadian Geoscience Foundation that will support our activities over the next two years, but in the long run the journal needs to become self-sufficient. It is critical that we retain our subscription base, and expand it whenever and wherever we can. We need to raise the profile of Geoscience Canada as widely as possible through GAC's agreements with organizations such as the Geological Society of America and the Geological Society of London. A wider awareness of Geoscience Canada will expand our readership, which will bring in more article submissions, and in turn raise our profile even more. We must also endeavour to broaden the scope of the journal - we are very diverse already, but there remain active areas of Earth Science that are rarely featured in our pages. Over the years, we have published many papers that have proved invaluable as instructional tools. We must continue to emphasize this vital role, with the idea that undergraduates become familiar with Geoscience Canada at an early stage, and remain with us throughout their professional careers.

I believe, as does Brendan, that there is no reason why Canada cannot produce a multidisciplinary journal of the highest stature. I am struck by the great progress that has been made towards this goal over the last few years. We need to maintain this momentum, even as we venture into some uncharted waters, such as the growing movement towards open-access publishing. It goes without saying that we will need your support in order to continue and complete this journey. We need your support as readers - not only to use what we publish, but to raise awareness of the journal with colleagues and collaborators. We need your support as interested volunteers - to review papers and provide advice to authors, to be series editors for thematic papers, or to assist us with copyediting. We need your support as teachers and educators - to use the resources of Geoscience Canada in the classroom, and to use it to bring your own insights to the students of others. Above all, we need your support as researchers and writers to submit the well-written and thought-provoking papers that are the hallmark of this journal. Geoscience Canada has a mandate that extends throughout our Geoscience Community and it is in many respects your journal. Its continued success depends on you as much as it does upon the efforts of its editorial and production team.

Andrew Kerr

Memorial University

Department of Earth Sciences

St. John's, Newfoundland and Labrador

Canada, A1B 3X5

akern@mun.ca 